the reticent community consensus on violent responses to specific kinds of social challenges does not exist amongst them. On the other hand, the act of deliberate communication already has roots in the intention to understand each other and to cooperate for common ends. Given this kind of post-mortem personal intervention in political matters, it seems more appropriate to deal with the Ghandian experience than with Montesquieu's warning.

Violence aside, the question of "naïvety" still needs an answer. Based on what has been argued so far, one can say that the feasibility of generating awareness, self-reliance and direct democratic relationships among refugees and forced migrants largely depends on their reasonable access to political and material facilities for horizontal social communication, both locally and internationally. Should there be insufficient access to none at all, then refugees will remain in a state or vertical dependence and sociopsychological isolation, surviving on humanitarian assistance, and continuing to be uninvited and paralyzed guests everywhere. Meanwhile manpowerwasting, money-consuming paternalism over refugees reigns.

Alternatively, with the facilities for horizontal communication, these people, wholly dependent today, could feel like adults, useful and at home in their new place of residence, in the same way as those migrants who have enough hard cash in their pockets. Furthermore, they would be able to fill the gap and demonstrate a new pattern of democracy: the reliance on multicultural exchanges, the constructive exercise of their human rights, the taking of direct, personal responsibility for themselves and for their social environment. We are on the threshold of a world-wide information society, where individual responsibility and participation is expected to play an increasing role. Therefore, this "new pattern of democracy" could be a sensible reward for the rest of us as well.

But, as long as refugees and forced migrants do not take on these responsibilities for themselves and for each other, agencies-granted "refugee involvement" will continue to replace the firm penetration of democracy in refugee affairs.

Geza Tessenyi is the coordinator of the Displaced Citizenship Programme at the Institute of Social Studies, The Hague, Netherlands.

\title{
The Evolution in Perception of the Role of the RHO
}

\author{
by Sam Laredo, Elaine Pollock and Jan Marshall
}

The new Convention refugee determination system created the need for a unique participant on the determination hearing, the refugee hearing officer (RHO). The RHO is, in short, a neutral participant at the full hearing before the Refugee Division. Authority for the existence of board counsel is provided in the Act and is amplified slightly in the Convention Refugee Determination Division Rules, but little practical guidance regarding the RHO's role can be gleaned from these sources. It is primarily the underlying policy and legal considerations governing the activities of the RHO which have determined the parameters of the role.

Although it has been assumed by some that the role of the RHO has evolved since implementation of the new determination system, in fact there has been no significant modification or rethinking of the role itself. What has occurred over the past several months is an increased understanding of the role on the part of the Convention Refugee Determination Division (CRDD) members, counsel and the RHOs themselves. There is a broader acceptance of the RHOs' participation in hearings resulting in a level of participation which actually accords with the role's established boundaries.

The primary difficulty encountered in explaining the role is that it is unusual and does not correspond with the familiar adversarial framework. This, of course, stems from the context in which the RHOs function. The determination hearing before two members of the IRB has been termed "non-adversarial", an expression which is accurate if not particularly illuminating.

Essentially, at the full hearing there is no party to the hearing who acts as an adversary to the claimant. But for a handful of cases, the legislation does not allow for the presence of a party whose role is to advocate a negative determination. (Except in certain specific circumstances, the Minister does not participate in the proceedings). During the hearing the panel is present to perform the adjudicative function and the claimant, usually with counsel, is present to provide evidence in support of the claim and to advocate a positive deter- mination. The position of RHO exists in order th have a participant who is trained to perform the investigative function before and during the hearing, to assist the panel during the hearing and to help ensure the hearing process is fair and complete. Importantly, the premise underlying the delineation and performance of these functions is that the RHO is a neutral participant in the proceedings and therefore does not take a particular position regarding whether or not the claimant ought to be determined a Convention refugee.

As a neutral participant, the RHO need not raise only those issues or analyses which might be to the benefit of the claimant, nor does the RHO focus only on those aspects of the claim which might be detrimental to the claimant's case. Rather, the RHO raises evidentiary and legal issues for the purpose of providing the panel with an informed view of the claim before it. In other words, the RHO does not avoid raising potentially damaging issues simply because the hearing is termed non-adversarial. Instead, the RHO places those issues in perspective and provides alternative analyses of the evidence and the law in order to assist the panel in formulating its decision.

\section{The RHO}

The authority for the creation of the position of the refugee hearing officer is found in section 67 (1) (a) as enacted by An Act to amend the Immigration Act, 1976 (formerly Bill C-55), S.C. 1988, chapter 35, section 18. The section provides that the Chairman of the Immigration and Refugee Board "may make rules (a) governing the activities of, and the practice and procedure in, the Refugee Division and the Appeal Division, including the functions of counsel employed by the Board;" (emphasis added) 
Another important point which has needed clarification is that the RHO is not required to be passive in order to ensure neutrality. Vigorous, persistent and probing questioning of the claimant by the RHO and assertive participation during the hearing has been thought by some to be inconsistent with the spirit of a non-adversarial hearing. As a result, it has been necessary to emphasize to the other parties that the RHO can only be effective if he or she fully participates in the hearing; being assertive in eliciting all relevant evidence is not synonymous with being adversarial.

The RHO not only elicits as much relevant evidence as possible but offers alternative interpretations of inconsistencies in that evidence to the panel and provides information on possible applications of the law in the area, without attempting to persuade the panel to take a particular position.

The training that newly-hired RHOs undergo has been modified somewhat since the first training session in October 1988 , primarily in response to the type of concerns explored above. Initially, the training sessions emphasized the "nonadversarial" aspect of the role; however, this seemed to lead to occasional confusion in practice. The RHOs expressed uncertainty regarding the extent and tone of their participation in the hearings and, quite understandably, often chose to exercise caution when faced with a novel situation. Some counsel expressed resistance to any involvement of the RHO in the hearing process and some panel members were unsure of the purpose of the RHO's presence at hearings. It has been difficult to ensure that all participants at the hearings have a fully informed perspective on the role of the RHO; people absorb new concepts at very different rates. It is also worth noting that the role of the RHO, being new, was subject to misunderstanding.

Soon after implementation of the new system, it became clear from the type of functional guidance being requested that most RHOs understood that they were not to act as adversaries at the hearing but were unsure of how far they could go in eliciting all the relevant evidence for the panel.

One example of this is the small controversy surrounding the use of the term "cross-examination". Cross-examination is associated with adversarial proceedings simply because almost all legal proceedings are adversarial. Consequently, cross-examination has come to be seen as the means by which one attempts to discredit the testimony of a party. In fact, The Concise Oxford Dictionary defines "crossexamine" as to "examine (esp. witness in lawcourt) minutely to check or extend previous testimony". This is, in effect, what the RHOs are supposed to do in questioning the claimant; they must organize, test and expand the testimony for the benefit of the panel, but from a neutral perspective. However, in an effort to avoid relaying conflicting signals to the RHOs, and to counsel, there was a tendency to avoid referring to "cross-examination" in the early RHO training sessions.

The concerns raised by RHOs started to make it clear that camouflaging neutral cross-examination behind the word "questioning" had actually contributed to uncertainty. As a result, in recent months the RHOs have been encouraged to be more persistent and probing in their questioning. or, in other words, to engage in crossexamination. Questioning that stops short of cross-examination is normally so ineffectual as to be unnecessary.

Another area which had been the focus of much discussion was the issue of whether RHOs should have access to information and evidence obtained by Case Presenting Officers (CPOs) before and during a claimant's initial hearing held before

\section{CRDD Rules Concerning the RHOs}

Rule 2 of the Convention Refugee Determination Division Rules, SOR/89103 , provides that in these rules '"refugee hearing officer' means a person referred to in paragraph 67 (1) (a) of the Act who acts as counsel to the Board".

Rule 13 reads as follows: "The Refugee Division may be assisted with a claim or application by a refugee hearing officer who may, subject to the direction of the Refugee Division,

(a) file documentary evidence;

(b) call and question witnesses; and

(c) make written or oral observations." (emphasis added) an Adjudicator and a member of the Refugee Division. Some were of the view that RHOs shoud make use of all information obtained by CPOs, as well as the evidence from the initial hearing, in order to allow the RHO to "cross-examine on previous inconsistent statements" and to bring forward evidence which would undermine the claim. Another view was that the RHO should avoid making use of an evidence from the initial hearing since to do so would be inconsistent with the "non-adversarial" spirit of the determination hearing.

In the final analysis, it became evident that the greater the information before the panel, the better the decision. The risk to the claimant was contingent on his or her ability, at the Refugee Division hearing, to respond to questions regarding inconsistencies in the story. Evidence from the initial hearing which appeared, at first blush, to undermine the claim might be easily explained; apparently incriminating evidence might in fact be irrelevant to the issues central to a final determination. In any event, before making use of such evidence at the hearing, the neutral nature of the RHO's role requires that in all circumstances the evidence be disclosed beforehand to the claimant and counsel. The RHOs do not indiscriminately present any and all evidence which may have been forewarned by a CPO; the RHO and CPO perform very different functions within very different proceedings.

Much of the uncertainty regarding the extent and tone of the RHO's participation at the hearing has been resolved and there is a far greater acceptance of the presence of the RHO than existed when the RHOs first appeared at hearings. Nonetheless, on-going training of RHOs remains important since new issues continue to arise and established practices occasionally need re-evaluation. Just as important, however, are the continuing efforts which are made to enhance the understanding of the Refugee Division members and Immigration Bar of the role of the RHO; the RHO's ability to effectively participate in hearings is directly related to the other participants' perceptions of the role.

This article was prepared by Sam Laredo, Acting Director, Refugee Hearing Officers, $I R B$, with the assistance of Elaine Pollock and Jan Marshall, refugee hearing analysts. 